Article

\title{
Exploring Walking Behavior in the Streets of New York City Using Hourly Pedestrian Count Data
}

\author{
Jae Min Lee ${ }^{(1)}$ \\ School of Architecture, University of Ulsan, Ulsan 44610, Korea; jaemin.lee@ulsan.ac.kr \\ Received: 16 July 2020; Accepted: 19 September 2020; Published: 23 September 2020
}

\begin{abstract}
This paper explores hourly automated pedestrian count data of seven locations in New York City to understand pedestrian walking patterns in cities. Due to practical limitations, such patterns have been studied conceptually; few researchers have explored walking as a continuous, long-term activity. Adopting an automated pedestrian counting method, we documented and observed people walking on city streets and found that unique pedestrian traffic patterns reflect land use, development intensity, and neighborhood characteristics. We observed a threshold of thermal comfort in outdoor activities. People tend to seek shade and avoid solar radiation stronger than $1248 \mathrm{Wh} / \mathrm{m}^{2}$ at an average air temperature of $25^{\circ} \mathrm{C}$. Automated collection of detailed pedestrian count data provides a new opportunity for urban designers and transportation planners to understand how people walk and to improve our cities to be less dependent on the automobile.
\end{abstract}

Keywords: walking; automated pedestrian counting; urban design; thermal comfort

\section{Introduction}

Walking is receiving belated attention across the urban planning disciplines such as in public health, transportation, real estate, and urban design. Researchers have found that promoting walking and building walkable communities have significant effects on healthy living, energy savings, and enjoying the urban lifestyle [1-5]. Based on these studies, walking seems to be an essential element in creating a sustainable society.

There are many aspects related to walking. In transportation terms, walking is a trip from point A to $B$, as well as a choice of one transport mode among many alternatives. Walking can be classified as either essential trips for commuting or optional trips for recreational activities. The purpose and intensity of walking are heavily influenced by weather, microclimate, sense of safety, and physical environment. Thus, in urban design, walking is concerned with favorable environments, either shaded or sunlit, consisting of clean, pleasant, safe, and human-scaled pathways and sidewalks.

Many studies have dealt with walking in terms of volume of traffic [6,7], rational choice [8-10], irrational random behavior [11,12], reaction to visual cues [13], and as one of many social activities. These studies explored walking by conducting computer simulations [14,15], predicting behavior from mathematical regression [16,17], and observing and counting activities in a limited and controlled environment and timeframe [18-20]. However, few have explored walking as an omnipresent activity.

Adopting an automated pedestrian counting algorithm provided by Placemeter, we documented and observed pedestrian patterns on city streets. We recorded hourly pedestrian traffic at seven locations in New York City over six months to explore the collective walking patterns and reactions to change in the physical environment. This information will provide insights on walking for urban designers and transportation planners to improve predominantly automobile-dependent cities and lifestyles. This is an exploratory research to investigate pedestrian behavior in streets with the relationship to the thermal environment using automated pedestrian count. 


\section{Literature Review}

At the junction of public health, transportation planning, urban design, and urban planning, walking has been studied extensively to elucidate the behavior of pedestrian-related trips and in different physical environments. Transportation scholars regard walking as one of many modes of travel; thus, their mathematical estimations stem from land use and development density. Others emphasize the importance of the walking environment itself. Providing a decent walking environment and proximity to everyday destinations can attract more people to walk. Since walking is a form of physical activity, public health scholars have argued that providing a walkable environment leads to a healthier society overall. Environmental scientists and urban designers have paid attention to the physical conditions of the street, the weather and thermal comfort, and the setting of street features. In this section, we will survey previous studies on walking and explore the research gaps in the literature.

\subsection{Land Use and Transportation}

In the transportation planning literature, walking is highly associated with land use and density. Each type of land use (residential, office, retail) has a unique travel demand. Development density is translated into number of occupants and intensity of travel. Thus, combining land use and density, planners can predict the frequency of walking, similar to the choice of motorized travel [21]. Cervero and Kockelmann [22] added diversity of land use and design to density (the so-called 3Ds). Diversity refers to mixed use in a given block or district; also, the level of land use mix at the neighborhood level and the configuration of the street are closely related to pedestrian walking patterns. The distance between two destinations helps determine the mode of travel. A trip to a convenience store in one's neighborhood is usually made by walking or biking, while an out-of-neighborhood trip is traveled by vehicle [23,24]. Although design often refers to the quality of a space, including aesthetic characteristics, Cervero and Kockelmann referred to design as the configuration and connectivity of streets. The intensity of street crossings and intersections, sidewalk widths and relative proportions, and street fixtures such as lighting and plantings are related to intensity of walking. The larger and well-managed parks attract more people and invite people to walk further [25].

Lee and Moudon [26] refined the model by identifying specific parameters for public policies and program implementation. They argued that the distance measurements to routine daily destinations, or the 3D $+R$, are effective alternatives to Cervero and Kockelmann's 3Ds. Lee and Moudon found that Seattle's King County residents tend to walk more if their neighborhoods include everyday retail destinations such as groceries, markets, banks, eating/drinking establishments, and schools (first $\mathrm{D}=$ Destinations). The proximity from homes to neighborhood destinations is positively associated with walking (second D = Distance), and higher residential density (third D = Density) is strongly associated with increased walking.

Ewing and Cervero [27] and Ewing et al. [28] developed the D variables further, as density, diversity, design, destination accessibility, distance to transit, and demographics. Demand management of parking space through control of supply and cost also influences the intensity of walking. The high price and/or lack of parking space in the central business district (CBD) deters people from driving into the city center, leading them to use alternative modes of transport: the transit system, walking, or biking.

Walk Scores, a recently developed internet-based platform that rates walkability, is an example of evaluating the potential use of walking based on the distance to nearby neighborhood amenities. The rating system has a scale system of 0 to 100 based on the distance to nearby neighborhood amenities such grocery stores, cafés, eating/drinking establishments, theaters, schools, and retail shops. Researchers have validated the reliability of the Walk Score [29]. In Providence, Rhode Island, and four other US metropolitan areas, these researchers concluded that the Walk Score is a valid and reliable measure of access to walkable amenities. 


\subsection{Urban Design and Microclimate}

Precipitation, sunlight, and air temperature have the largest effect on walking. As the air temperature increases, more pedestrian activities are observed, and it has a direct impact on walking tempo [30]. Li [31] observed that casual activities declined when the air temperature fell to $4{ }^{\circ} \mathrm{C}$, the threshold of pedestrian activity. Researchers have found that thermal comfort in streets and plazas affected how people use these public open spaces-walking, sitting, and shade-seeking. At $4{ }^{\circ} \mathrm{C}$ to $20^{\circ} \mathrm{C}$, people prefer to be in the sun; only at around $20^{\circ} \mathrm{C}$ is there an equal distribution of individuals sitting in the shade and in the sun, implying people find them equally comfortable [32]. Behaviors within public spaces that can be related to perceived temperature-standing, sitting, and shade-seeking-followed the same patterns in both New York City and San Francisco, with a threshold temperature of $23^{\circ} \mathrm{C}$ for shade-seeking [33].

Montigny and Zacharias [4] found that a $5{ }^{\circ} \mathrm{C}$ increase in temperature was associated with a $14 \%$ increase in pedestrians. A shift from snow to dry conditions was associated with a pedestrian increase of $23 \%$, and a $5 \%$ increase in sunlit area was associated with a $2 \%$ increase. Using an automated hourly pedestrian counting device suggested that season and weather have an effect on pedestrian volume in downtown Montpelier, Vermont. Precipitation reduces the average hourly volume by approximately $13 \%$, and the winter weather reduces it by $16 \%$. At best, a combination of weather variables accounts for $30 \%$ of the variance in hourly volumes [34].

Microclimate also has been identified as an important element in public spaces [5,35-39]. Microclimates in the urban environment play a critical role in maintaining urban vitality and encouraging the frequent use of outdoor public spaces for desired outdoor activities by extending the days of comfortable temperatures. Understanding the dynamics between built form and thermal comfort, or the human reaction to the thermal environment, is important for urban designers. Microclimate factors, including sunlight, shade, air temperature, wind speed, humidity, and sky condition, can contribute to the use of outdoor space [25,30,40-43].

The public is always interested in the thermal comfort of public spaces, and appropriate urban design can actually improve microclimates and encourage more walking in streets, plazas, and parks. In Norway, for example, designs for favorable microclimate conditions were implemented, i.e., protection from cold wind, solar exposure, and avoiding overshadowing, which resulted in extending the outdoor season for up to six weeks into the spring and fall [44]. The residents of San Francisco are also eager to maintain microclimatic quality in open spaces, wanting protection from the winds or overshadowing caused by nearby new developments [45]. As a result, in 1985, the city of San Francisco established a set of design requirements to control the effects of all new buildings on the local microclimates of public spaces [46]. In a more recent example, in 2014, residents of New York City began campaigning for a moratorium on new buildings immediately to the south of Central Park. The Nordstrom Tower, 225 West 57th Street, a condo tower that rises to a height of 1770 feet, was casting a shadow over the playground and ball field [47]. However, in that instance, residents failed to retain their right to be sunlit in the park [48].

For microclimates in urban public spaces, design can improve existing conditions either at the earliest stage or later by design interventions. When the urban texture is extant, alterations to improve the microclimate are possible at the scale of the urban block, provided it is acknowledged that the public domain is not to be ignored. Vegetation used for shading and windbreaks, movable canvas awnings, and canopies made of various materials such as reeds, bamboo, or vines can provide effective shading while preserving the main architectural features of the street. Furthermore, proprietors of commercial activities are normally the first to realize the potential of such cool oases in a hot environment [44].

\subsection{Need for Research}

Studies have identified several factors affecting the volume of pedestrian traffic. Walking is one choice among many transport modes; land use and density are the major contributors to the total pedestrian volume. We can categorize walking into two types based on purpose: essential trips for 
work commuting and optional trips for recreational activities. Unlike the essential trips, the optional or recreational trips are more affected by the physical environment, including weather, microclimate, sense of safety, and configuration of streets and features.

Although walking is a conjunction of complicated dynamics, most studies have explored walking as isolated events related to a specific subject. Many studies have dealt with walking in terms of volume of traffic, rational choice, irrational random behavior, reaction to a visual cue, and one of many social activities. These studies explored walking by conducting computer simulations, predicting behavior from mathematical regression, and observing and counting activities in a limited and controlled environment and timeframe. However, walking as an activity in the real world is not clearly reproducible in a lab environment or in a computer simulation. The raw walking dataset contains much noise, and it is difficult to understand pedestrian behavior at a micro-level. Few researchers have explored walking as a whole or as an omnipresent activity taking place. Too much conceptualization can make it difficult to identify the complex mechanisms of walking. In this study, we use an automated pedestrian counting algorithm to explore pedestrian patterns on city streets.

\section{Materials and Methods}

\subsection{Data}

The primary data sources for this study were pedestrian count and relative speed data captured by Placemeter [49], weather data from Central Park weather station (KNYC) and other private weather stations in New York City [50], and sunlight and wind simulation results from massing models of the corresponding locations.

Placemeter is a New York City-based information technology consulting company that harvests pedestrian count data using computer vision technology. Placemeter produces video feeds from streets and creates automated reports tracking the number of pedestrians. Aside from the 0.1 percent of its videos that are saved for quality assurance, the company says the videos are discarded after being processed and converted into reports for customers [34]. For privacy concerns, Placemeter uses computer vision algorithms to analyze video for volume, speed, and trajectories of pedestrian and vehicular traffic in cities, rather than identifying specific individuals [49].

The hourly pedestrian count data provided by Placemeter were used to measure walking patterns in detail. The data were collected from seven locations on New York City sidewalks. Three of them were located within one block of one another and represented locations on both sides of the street, i.e., the west and east sidewalks. The "matched sidewalk" is pertinent to test the effect of the microclimate because opposite sides of buildings create distinctly different hourly microclimate conditions. Most built environments are very controlled except for sidewalk characteristics, e.g., number of entrances, transparency in retail frontage, and sidewalk width.

Weather conditions, precipitation, and air temperature are known to have effects on walking $[29,34]$. Here, the weather information was collected from Weather Underground, a private, web-based weather station interface that compiles weather data from automated personal weather stations (PWSs). These PWSs provide hourly and sub-hourly reports, including air temperature, dew point, relative humidity, wind speed, gust speed, wind direction, air pressure, and solar radiation energy [49].

\subsection{Climate Classification of New York City}

New York City is a humid subtropical climate under Köppen climate classification. The daytime average high is $28.1^{\circ} \mathrm{C}$ in August whereas the average low is $-2.5^{\circ} \mathrm{C}$ in January [49,51]. Winters are chilly and damp due to sea breezes from the Atlantic Ocean. The city is also the quintessential example of an urban heat island effect. Summer night temperatures are higher than the surrounding region due to the densely built urban area. 


\subsection{Monitored Streets}

We collected pedestrian count data from April through July 2015 at seven locations: the east sidewalk on 7th Avenue between 36th and 37th Streets (X7AW), both sides of York Avenue between 82nd and 83rd Streets (YKAW, YKAE), both sides of East 44th Street between 2nd and 3rd Avenues (E44N, E44S), and both sides of Sterling Place (STPN, STPS) (see Figure 1). One of the main streets in New York City is 7th Avenue. The monitoring location was two blocks north of Madison Square Garden, which is a tourist attraction for various events and performance venues, and Pennsylvania Station, where commuters from New Jersey and Long Island transfer to the local subway or walk to their final destinations. East 44th Street is located two blocks east of Grand Central Station and west of the United Nations Headquarters building. It is home to consulates and diplomats; therefore, little foot traffic is observed on the sidewalks. York Avenue is located in the Upper East Side, where new high-rise residential buildings are filling the neighborhood. The closest subway station is on the Q Line at 86th and 2nd Avenue; thus, the neighborhood is primarily serviced by a bus system, which slightly reduces street traffic. Sterling Place is a quiet residential street in Brooklyn with walk-ups and apartment buildings. These four streets present a considerable variety of neighborhood characteristics.

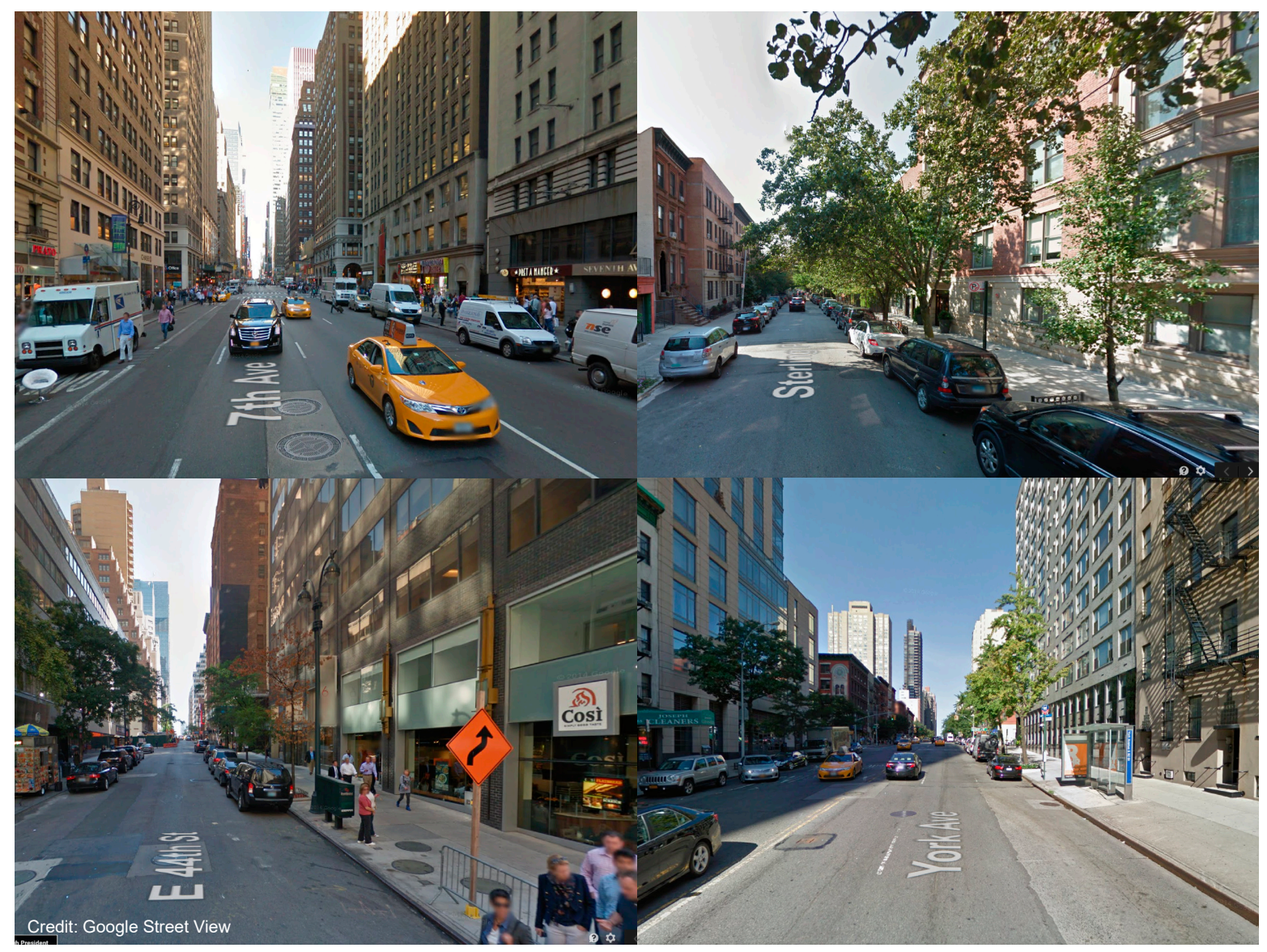

Figure 1. Monitored streets in New York City (top left: 7th Avenue (X7AW), top right: Sterling Place (STPN\&S), bottom left: E 44th Street (E44N\&S), bottom right: York Avenue (YKAW\&E). Images were taken from Google Street View, Map Data: (C2020 Google. 


\section{Results}

\subsection{Development Intensity, Land Use, and Pedestrian Count}

The patterns from automated pedestrian counts reflect the characteristics of the observed street. As seen in Figure 2, the total number of pedestrians passing the seven locations ranged from 20,000 to more than 50,000. Starting in June, the number of people walking on these sidewalks increased, especially at 7th Avenue, whereas the other streets maintained similar traffic. The difference can be explained by the nature of the streets as 7th Avenue is frequently visited by tourists, while the others are residential streets or high-density residential neighborhoods that do not attract tourist traffic. As discussed above, walking is usually categorized as essential or non-essential (necessary or optional trips) [5,52]. Non-essential and optional trips tend to increase in a pleasant physical environment, not too cold or hot, safe, connected, and well-designed [5,16]. The surge of pedestrian traffic at 7 th Avenue starting in June can be attributed to non-essential and optional trips. Compared with the change in air temperature, it is clear that air temperature and foot traffic on commercial streets have a positive correlation.

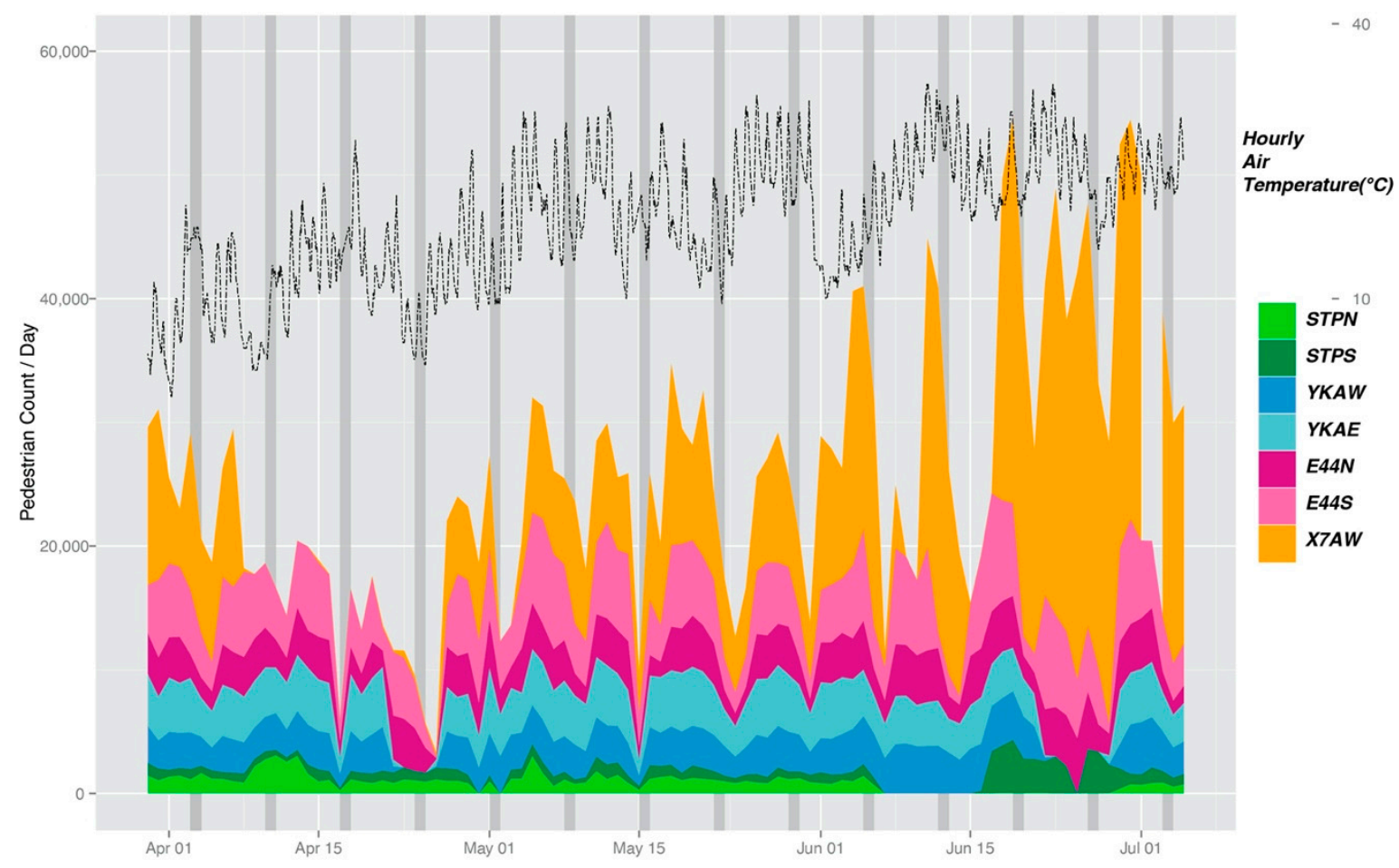

Figure 2. Seasonal changes of pedestrian counts from April to July 2015. Pedestrian traffic increased from June onward, especially on the east sidewalk of 7th Avenue (X7AW), while the others did not show dramatic changes over those months.

The other three streets did not show a dramatic increase in pedestrian traffic. Rather, the foot traffic volume of these streets was consistent throughout the monitored period. As per Gehl [5], necessary activities can take place regardless of the physical environment; trips to the grocery, work, and home are needed regardless of the weather. The patterns of pedestrian traffic can give us insight into how people use streets.

The pedestrian count patterns showed distinct characteristics according to land use. Each land use type showed a unique walk count pattern by hour, day, and weekday versus weekend. Figure 3 is a graph of pedestrian count at 7 th Avenue by time of day and by month. As described above, a higher volume of foot traffic was observed in June and July. Comparing average pedestrian counts by month, 
more than twice the volume of foot traffic was observed in those two months, likely due in part to tourists. Figure 3 also shows that the intensity of activities differs by month. In general, the hourly average shows three peaks: morning rush hour, lunch, and evening rush hour. Of those peaks, lunch shows the highest traffic volume, likely because more people walk to lunch. In the warmer months, however, the hourly average for evening rush hour traffic is similar to that at lunch, which indicates that the additional trips are for purposes other than commuting.

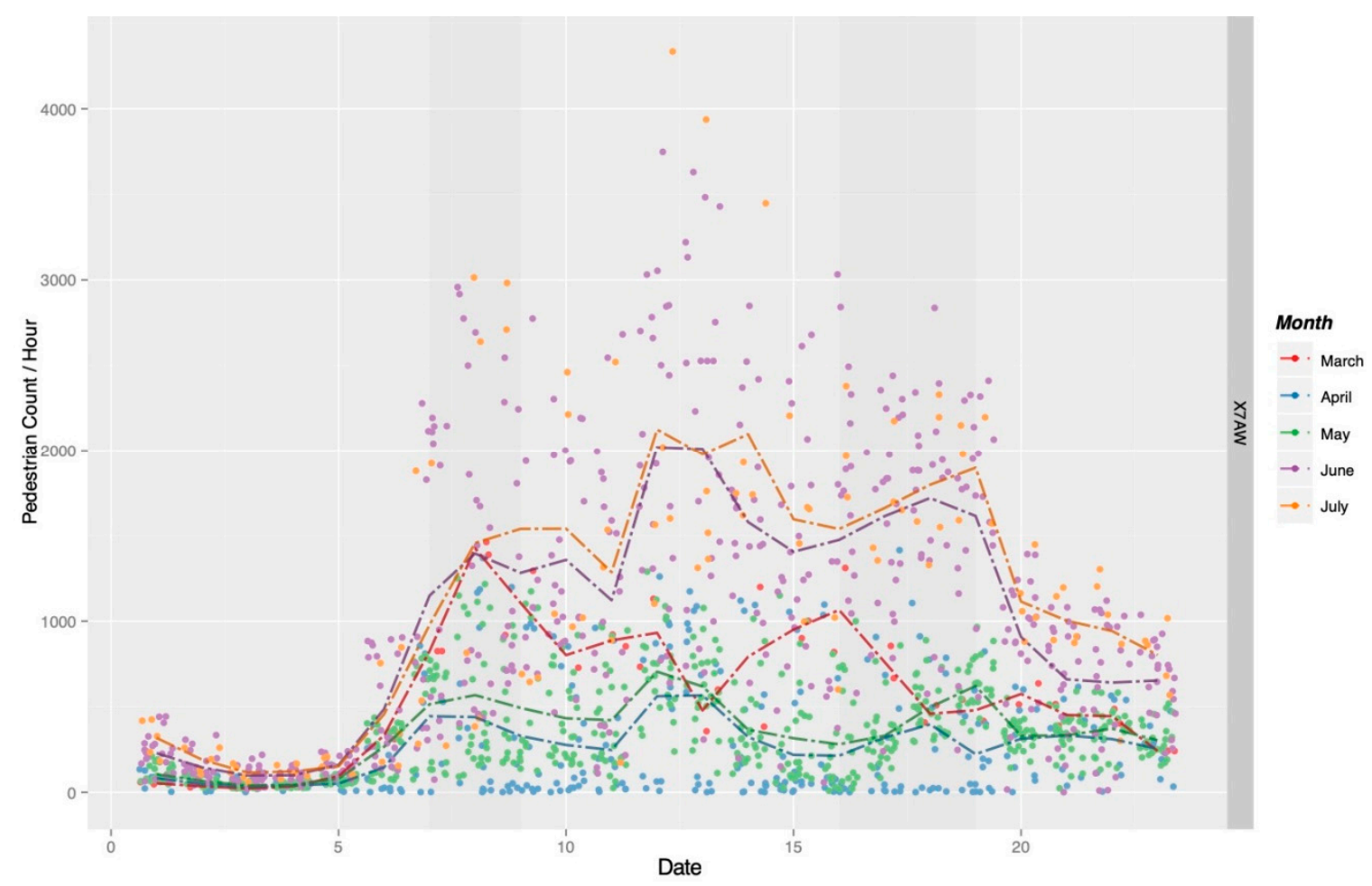

Figure 3. Pedestrian counts by hour at 7th Avenue (Midtown CBD, FAR 12.5, office 69\%, retail 11\%, residential 5\%). A higher volume of traffic was observed in June and July. Comparing the June/July and April/May average lines, the sidewalk was as busy in the evening as at lunch time (single observation and average lines).

Automated pedestrian traffic showed different magnitudes and patterns by land use. The streets we observed ranged in characteristics from $\mathrm{CBD}$, office, high-rise residential, and walk-up residential, representing the spectrum of urban places. Figures 3-6 show a unique pattern for each land use. First, pedestrian traffic in the office district (Figure 4) shows three peaks representing rush hours and lunch. Residential streets (Figures 5 and 6) do not show the peaks found in office districts; instead, there is a flat plateau from morning to evening at both York Avenue and Park Slope. A higher volume of foot traffic is spread from afternoon to evening, attributable to density: York Avenue in the Upper East Side has a building density of FAR 5.6, whereas Sterling Place in Park Slope is only FAR 2.1. 


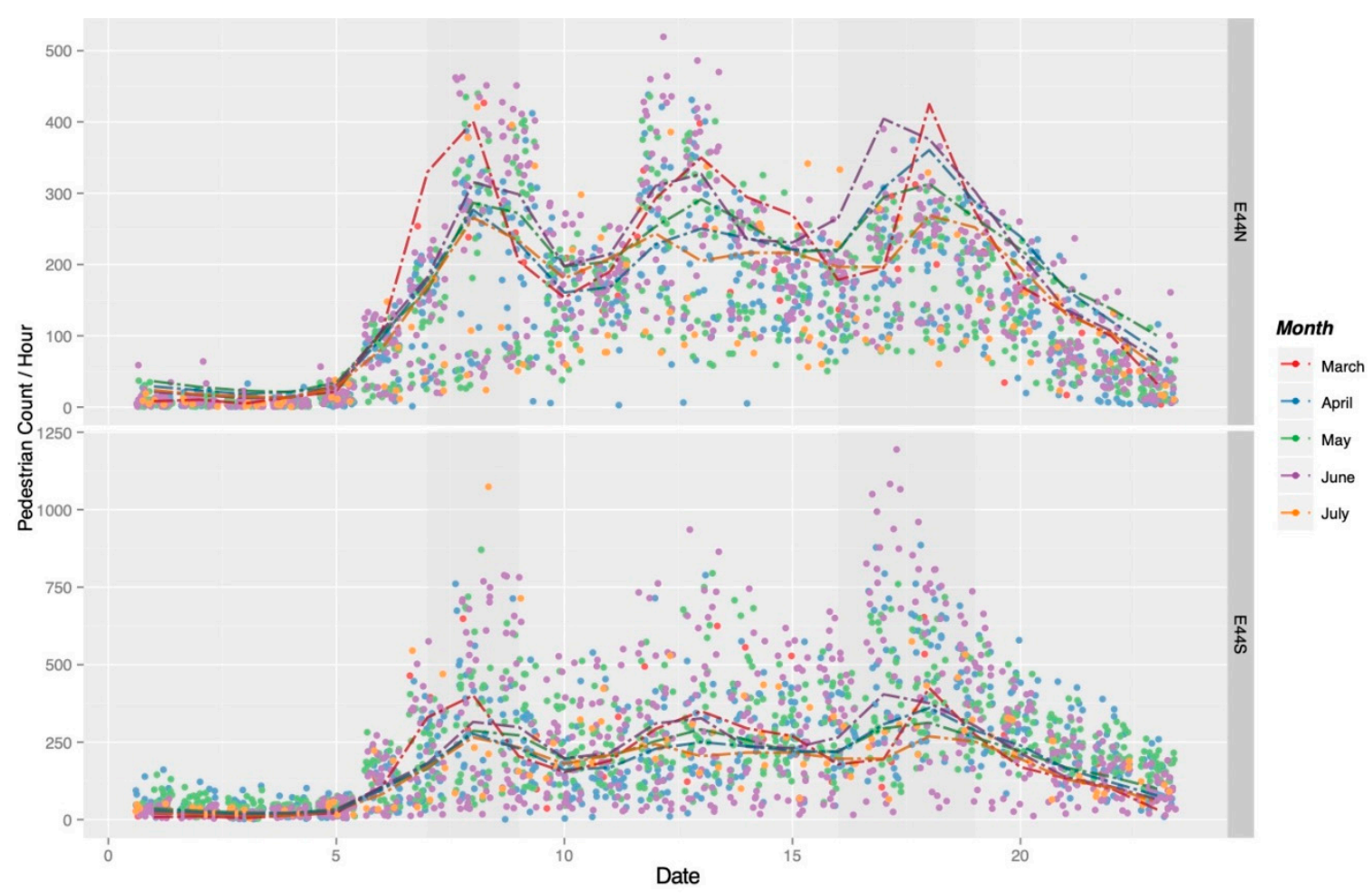

Figure 4. Pedestrian counts at East 44th Street (Midtown Office District, FAR 10.2, office 67\%, retail 3\%, residential 23\%) (single observation and average lines).

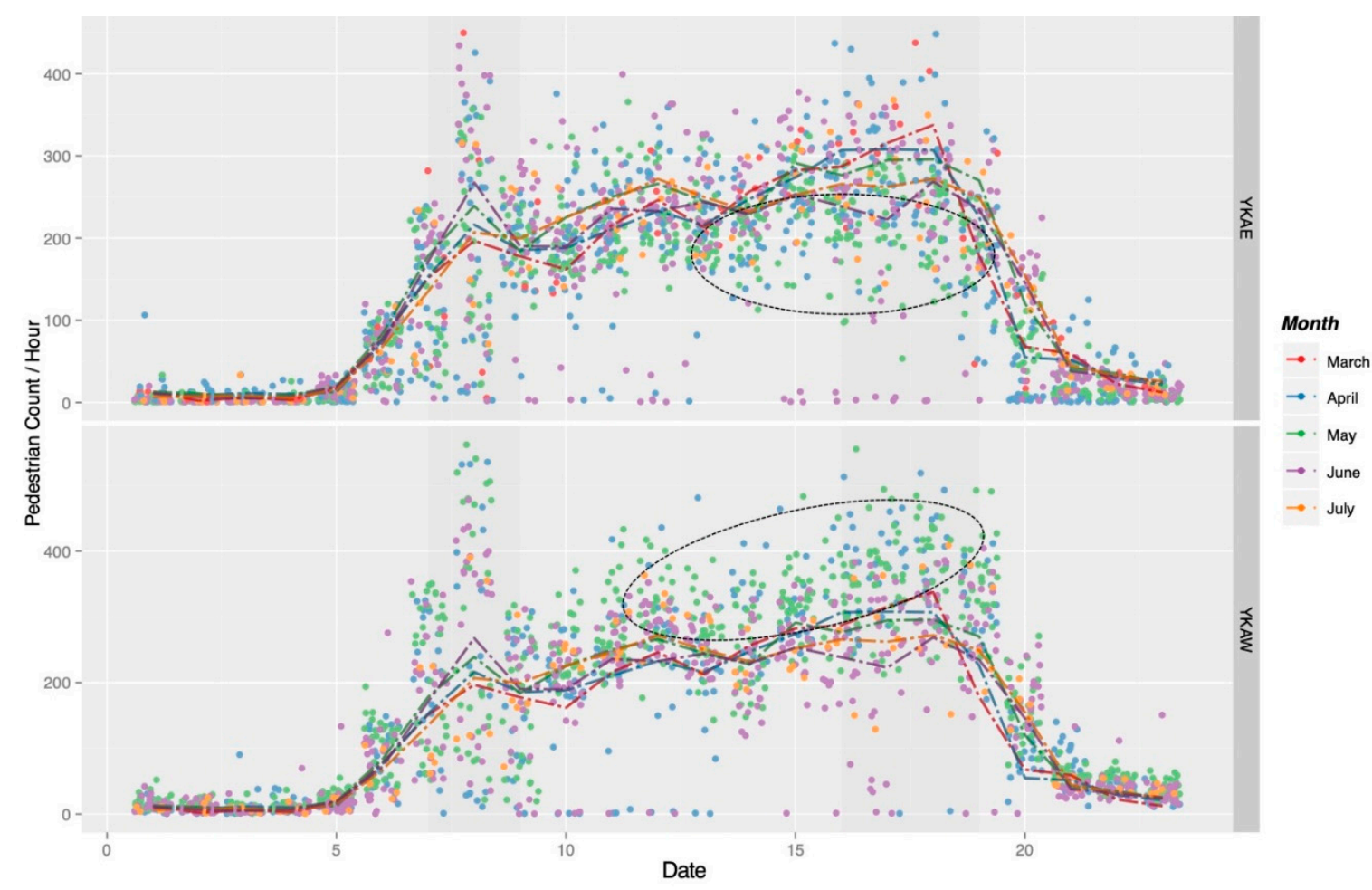

Figure 5. Pedestrian counts at York Avenue (Upper East Neighborhood, FAR 5.6, office 1\%, retail 2\%, residential 90\%) (single observation and average lines). 


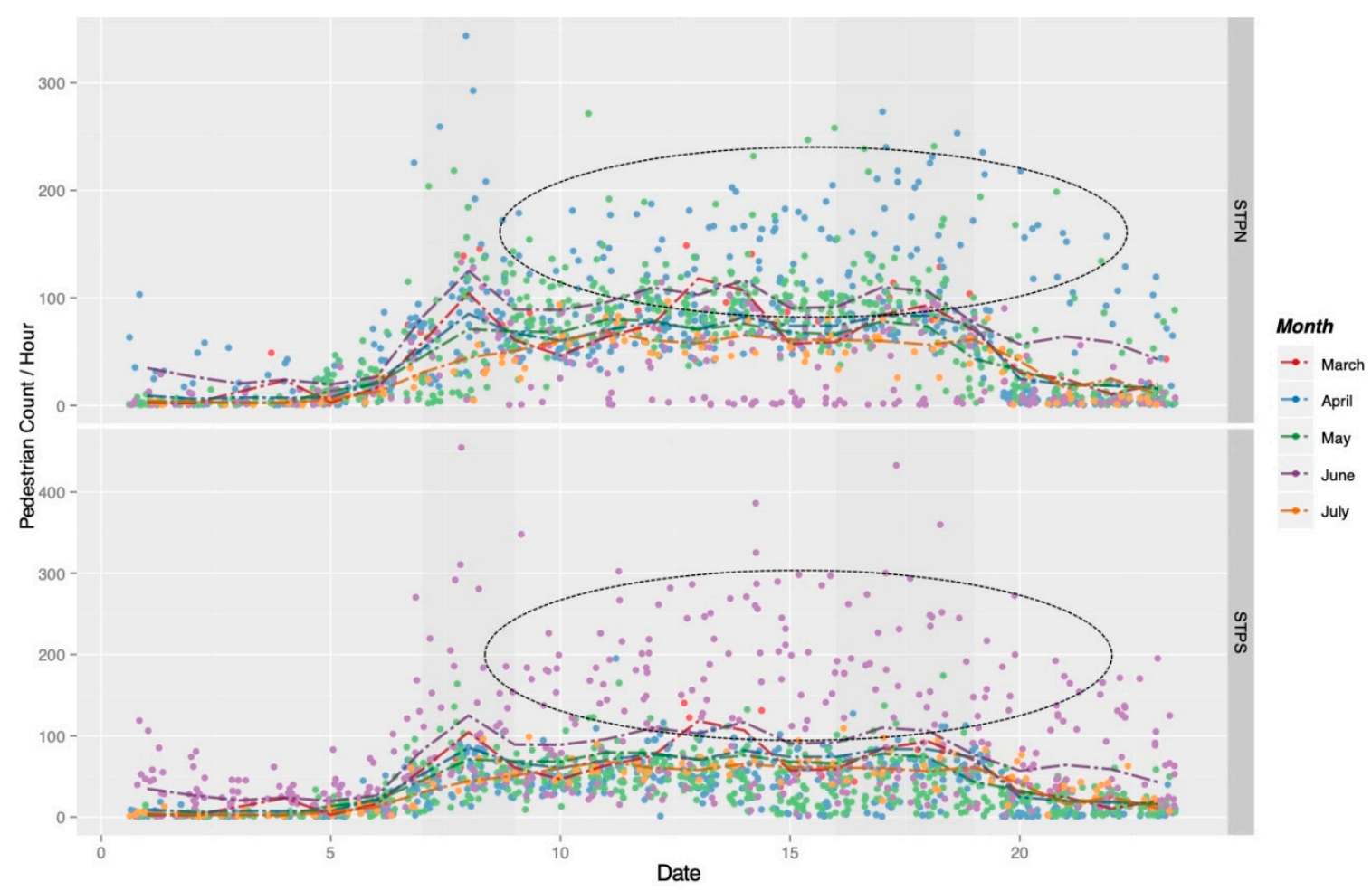

Figure 6. Pedestrian counts at Sterling Place (Park Slope Brooklyn-Residential, FAR 2.1, office 1\%, retail $7 \%$, residential $82 \%$ ) (single observation and average lines).

Screening pedestrian count by weekday against weekend provides an idea of how neighborhood characteristics change. As seen in Figure 7, the weekday foot traffic pattern shows three peaks, as in other office districts. However, the weekend pedestrian count pattern resembles that of a residential neighborhood, with a plateau from 9 a.m. to 6 p.m. The average foot traffic for the weekend is about $27 \%$ that of weekdays, which is close to the land use mix of $23 \%$ residential use.

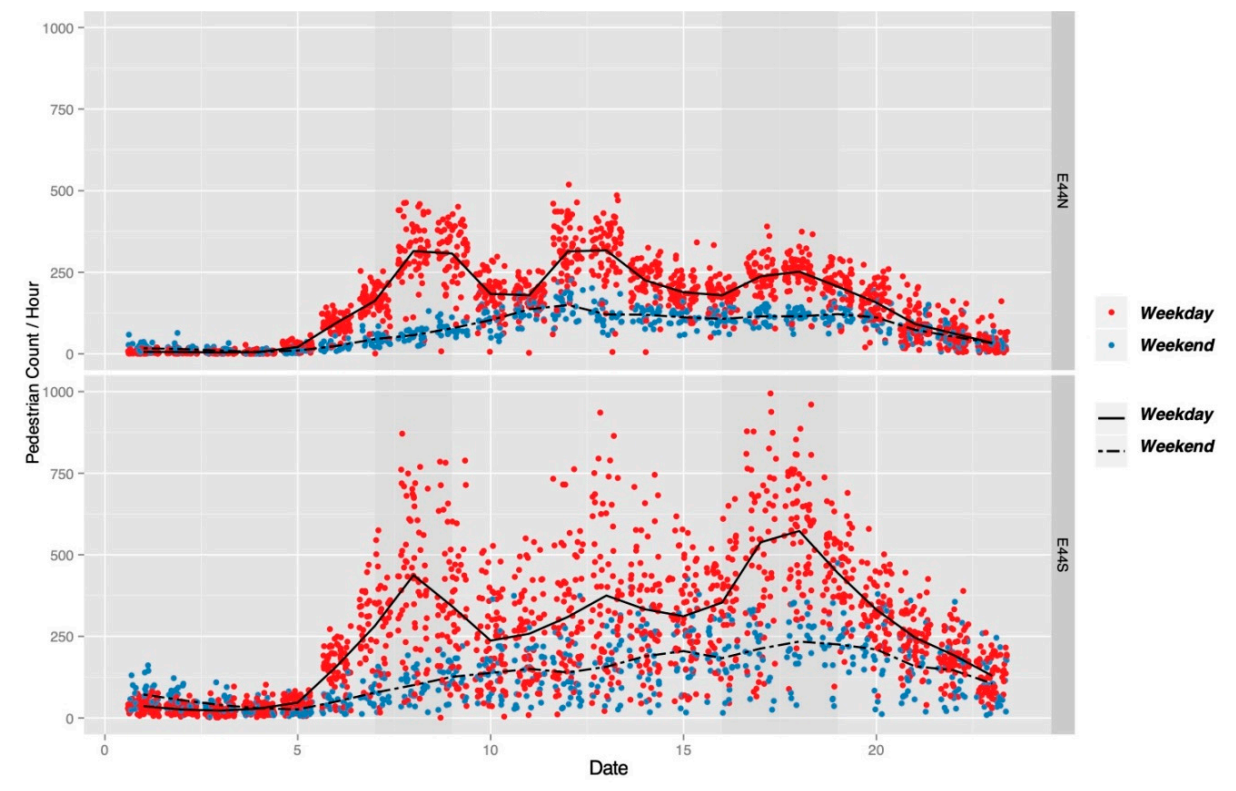

Figure 7. Weekday versus weekend pedestrian count comparison at East 44th Street (single observation and average lines). 
As discussed above, urban planners and designers can study pedestrian patterns on city streets by examining detailed pedestrian counts. Magnitude of foot traffic volume and distinct patterns of hourly count data are associated with land use and development density. Exploring the automated pedestrian count can have many benefits, and future research needs to examine the correlation between count data and land use intensity in a cross-sectional manner to estimate and predict foot traffic in city streets.

\subsection{Outdoor Thermal Comfort and Pedestrian Count}

A positive correlation between outdoor thermal comfort and pedestrian traffic has been widely established in urban design $[5,16,38,39,53]$. More people tend to walk outside for non-essential, optional, social, or recreational purposes on warmer days. This is a general pattern that can be observed regardless of location.

Detailed pedestrian counts indicate a threshold that changes people's walking behavior. As highlighted in the dashed circles in Figures 5 and 6, pedestrians tend to prefer one side of the street over the other during certain months. For example, more people walk on the east side rather than the west side of York Avenue in May. Green dots appear below the average of the east sidewalk, while those of the west sidewalk are above the average. This seasonal difference is clearer at Sterling Place. In April and May, more blue and green dots appear above the average on the north sidewalk. On the contrary, purple dots (June) are above the average pedestrian traffic on the south edge of the street.

We explored why people shift from one side to the other side of the street. One hypothesis is that the land uses of the street vary considerably. On Sterling Place and York Avenue (see Figure 8), the two sides of the street have different numbers of entrances facing the sidewalk, numbers of planted trees, and types of buildings. However, since they are similar types of street, the differences are nominal, and the land use conditions did not change during the study period. Therefore, such differences do not explain the temporal changes in pedestrian traffic volume.
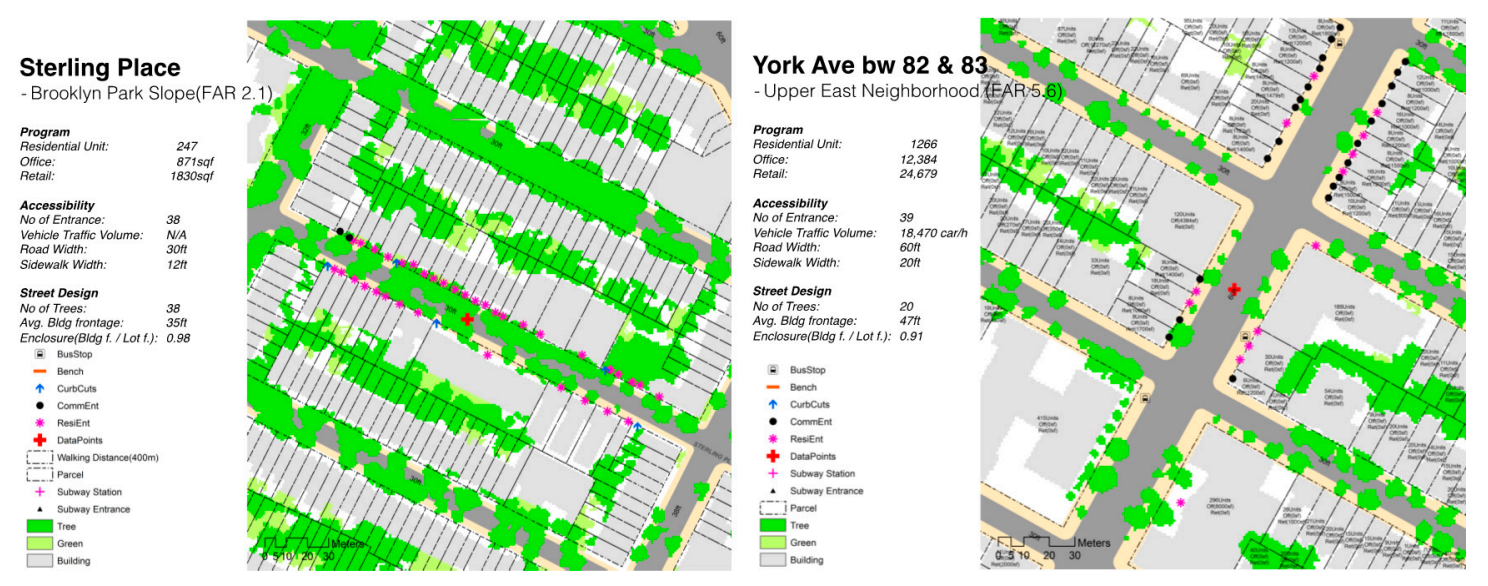

Figure 8. Land use features of the two sets of paired sidewalks (left: Sterling Place, right: York Avenue) [54].

Another hypothesis is that microclimate is the determining factor. By comparing the physical environment or microclimate of the two sidewalks, we found that people tend to choose a more pleasant sidewalk. Figure 9 is the detailed walk count graph of York Avenue sidewalks, showing that the foot traffic volume of the east sidewalk surpassed that of the west sidewalk during April and May. However, from the beginning of June onward, the west sidewalk shows more pedestrian traffic than the east side. As seen in Figure 2, the air temperature increased from April to May, but the temperatures of May $\left(77.1^{\circ} \mathrm{F}\right)$ and June $\left(78.8^{\circ} \mathrm{F}\right)$ were not dramatically different. June was slightly warmer than May on York Avenue, which suggests that air temperature was not a determinant above a certain level. 


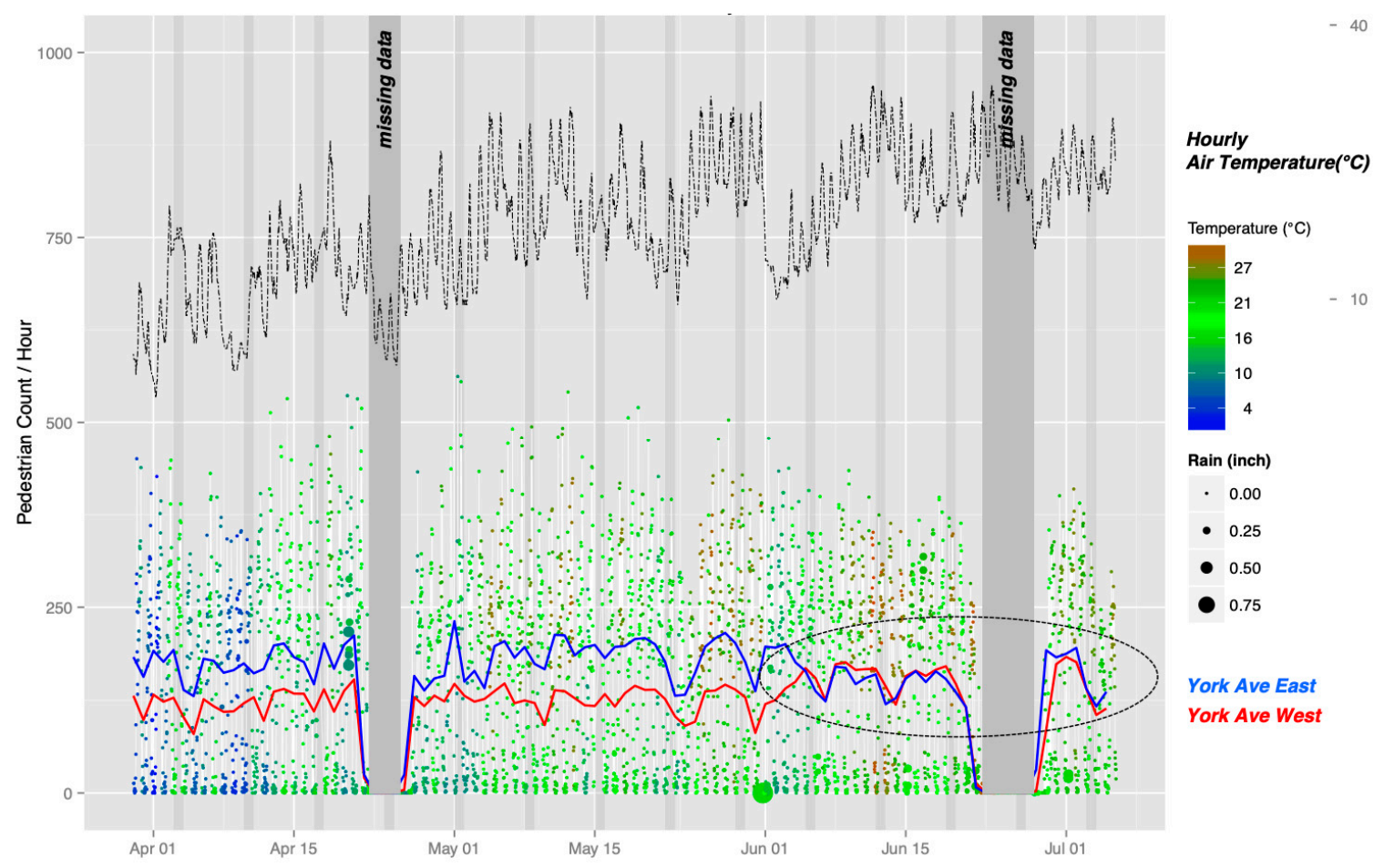

Figure 9. Hourly pedestrian counts on York Avenue. From early June, people tend to shift from the east sidewalk to the west one to avoid harsh sunlight and to seek shade in the afternoon.

Air temperature was not a critical factor for why people changed their preferred side of the street on York Avenue. Instead, sunlight and shading were the main determinants when the weather was warm enough. York Avenue is usually busier in the afternoon, as seen in Figure 5; the average pedestrian traffic is highest around 6 p.m. We observed less foot traffic on the west sidewalk compared to the east before June. However, from 12 p.m. to 6 p.m., more foot traffic was observed on the west sidewalk of York Avenue. The biggest difference between the two sidewalks is the amount of shade produced by the adjacent buildings. The afternoon sunlight on the east sidewalk creates a pleasant walking environment until May but tends to be strong starting in June, motivating people to cross the street to find shade.

\subsection{Solar Radiation and Pedestrian Behavior}

Solar radiation increases from winter to summer as the sun's altitude changes, as shown in Figure 10. In our data, the maximum sun radiation in December was $601 \mathrm{Wh} / \mathrm{m}^{2}$ compared to $1250 \mathrm{Wh} / \mathrm{m}^{2}$ in June (twice as strong in June). From May to July, the solar radiation ranged from 1200 to $1250 \mathrm{Wh} / \mathrm{m}^{2}$. The increase in foot traffic on the west sidewalk was observed from June onward, when the solar radiation reached $1248 \mathrm{Wh} / \mathrm{m}^{2}$. Considering that the air temperatures were similar in May and June, an average of $25{ }^{\circ} \mathrm{C}$ against $26^{\circ} \mathrm{C}$ solar radiation was determined as the major reason why people shifted their preferred side of the street. That is, the combined air temperature, wind, humidity, and solar radiation was uncomfortable enough for people to make additional street crossings to find thermal comfort. Thus, on York Avenue in New York City, the solar radiation tolerance for a pedestrian was roughly $1248 \mathrm{Wh} / \mathrm{m}^{2}$ at an air temperature of $25^{\circ} \mathrm{C}$. 


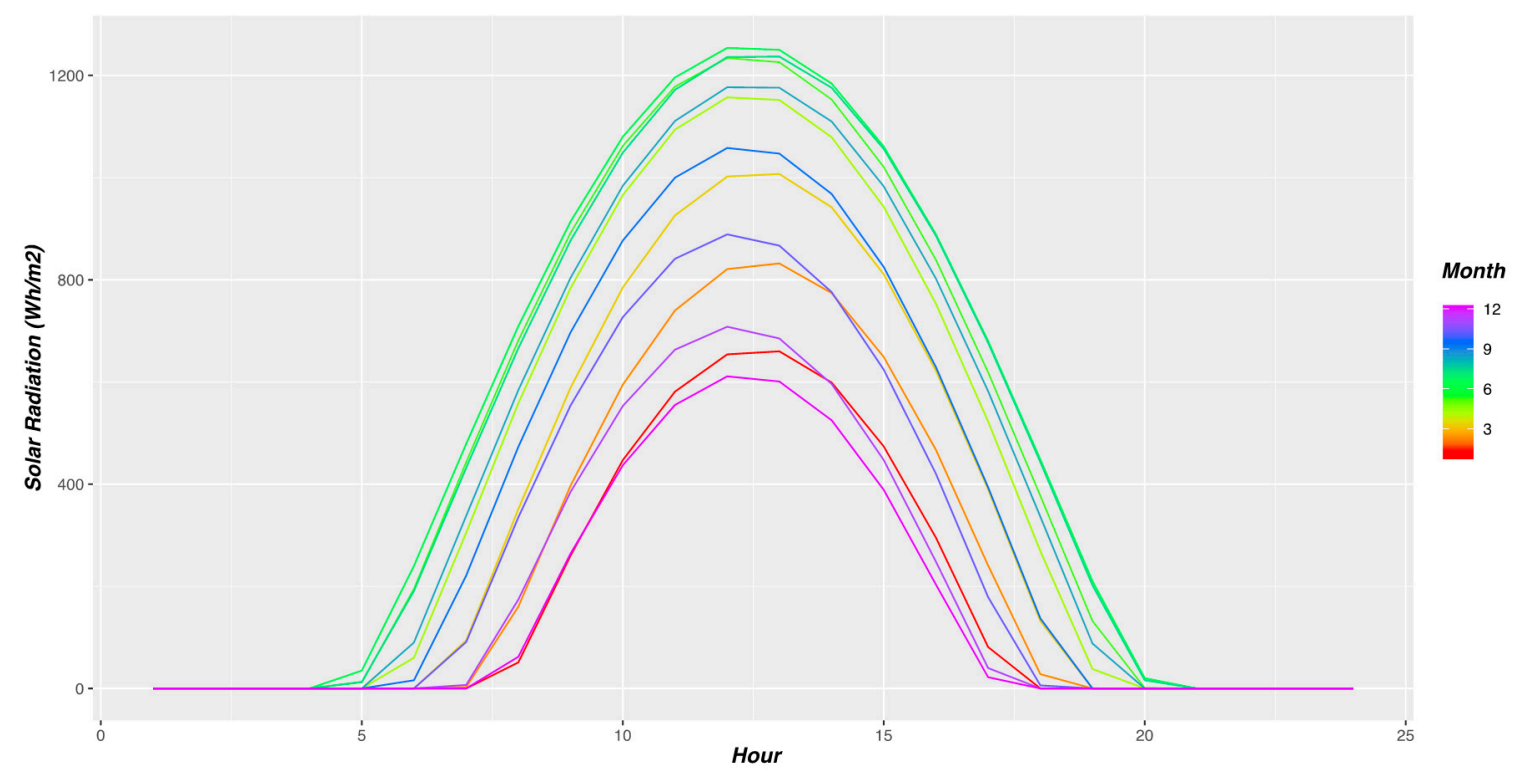

Figure 10. Insolation by month (sunlight watt $/ \mathrm{m}^{2}$ ).

The effect of solar radiation was also clear on Sterling Place. Figure 6 shows the temporal difference in pedestrian sidewalk preference. More foot traffic was observed in April and May, and more of the traffic was on the south sidewalk in June. In other words, people enjoyed the sunlight in early spring but tended to cross the street when it became too strong. The south sidewalk is shaded by the adjacent buildings and is thus relatively more comfortable than the sunny north sidewalk. This transition occurred at the same time as on York Avenue when the solar radiation reached $1248 \mathrm{Wh} / \mathrm{m}^{2}$.

Unlike the other two sets of sidewalks, East 44th Street did not show particular changes over the year. The level of solar radiation for the two sidewalks was not different because the surrounding buildings shade both sidewalks.

\section{Discussion}

\subsection{Detailed Pedestrian Count Data}

Automated pedestrian count data can provide insight into how people navigate cities. Although manual observation of public spaces has many benefits, it is difficult to collect around-the-clock data at multiple locations. Automated pedestrian counts can supplement manual observation by expanding coverage to include day and night, winter and summer, and sunny and rainy days. Exploring the pedestrian counts and identifying patterns can help elucidate how people use public spaces and walk around in cities. Adopting pedestrian counts can help urban designers and transportation planners to posit new, as well as confirm, established theories of walking.

As described earlier, examining hourly pedestrian data and comparing the times of day, week, and year provided lessons in understanding the characteristics of streets. The greater seasonal changes in foot traffic indicated a greater number of tourists or temporal visitors. The difference in weekday and weekend foot traffic can help estimate the ratio between office and residential use, and the total volume of foot traffic represents the development intensity of a neighborhood.

The primary character of a street reflects the pattern of foot traffic. The number of traffic peaks and their height indicate the primary land use, such as the foot traffic pattern of three peaks in the morning rush hour, lunch, and evening rush hour in association with commuting and lunch breaks. In contrast and regardless of density, a plateau pattern without those three peaks represents a primary residential use of the neighborhood. 
As summarized below, detailed pedestrian count data can provide a comprehensive pattern of how people walk and use streets in cities. This can be a useful tool for urban designers to explore pedestrian behavior and the surrounding environment in the following aspects:

- Seasonal change in foot traffic-visitors and tourists

- Differences between weekday and weekend foot traffic—office and residential uses

- Total volume of foot traffic — development intensity of a neighborhood

- Three peaks in foot traffic pattern-office as primary land use

- Plateau in foot traffic pattern-residential as primary land use.

\subsection{Thermal Comfort Threshold}

This study confirms previous research and findings which show that thermal comfort has a major effect on walking. In a comfortable environment, people tend to perform more optional and recreational trips, resulting in a higher volume of foot traffic. The effect of thermal comfort is clearly represented in the paired sidewalks of York Avenue and Sterling Place. For various reasons, people tend to show similar walking patterns. They choose one side of the street over the other because of their origin or destination location, because they prefer certain building façades, or because they feel safer and more comfortable. On York Avenue and Sterling Place, many pedestrians changed their preferred sidewalk when the thermal comfort factors changed. A clear shift took place in April and May on the west sidewalk of York Avenue and the north sidewalk of Sterling Place: both were popular passageways until people changed their sidewalk preference starting in June.

Paired sidewalk observation provides insights on threshold thermal comfort resulting in behavior change. From the York Avenue and Sterling Place cases, the main factor that led people to change their sidewalk choice was solar radiation. Since the air temperature in May and June was relatively constant, the increased level of solar radiation in June drove pedestrians to seek shade; thus, the shaded sidewalks showed higher volumes of foot traffic. The solar radiation was $1248 \mathrm{Wh} / \mathrm{m}^{2}$ with an air temperature of $25^{\circ} \mathrm{C}$ when the shift was observed. This threshold is a new parameter to guide the design of streets and buildings to promote walking in cities.

\subsection{Street and Public Space Design}

There have been many debates on whether or not a built environment affects people's behavior. Thermal comfort and outdoor activities are closely related to each other. Improved thermal comfort allows more people to stay outdoors for extended periods, thus creating more chances to associate with other people. In walking, pleasant weather and thermal comfort provide more options for people to travel. Thus, to promote walking, street and buildings should be designed to positively contribute to thermal comfort in public spaces.

Based on the findings of this study, streets and plazas in cities would be better utilized when the solar radiation does not exceed $1248 \mathrm{Wh} / \mathrm{m}^{2}$. There are different ways to achieve this goal, including building shading, tree planting, and installing shading devices. Public space designers and managers need to provide enough shaded space in the hotter months.

\section{Conclusions}

Examining automated hourly pedestrian count data presents new opportunities to understand pedestrian patterns in cities. Unique patterns of foot traffic are associated with land use, development intensity, and the characteristics of the neighborhood. The discrepancy in the volume of foot traffic indicates the number of visitors and tourists in summer versus the number of residents in winter. The difference between weekday and weekend foot traffic volume shows the divide between office and residential uses of the neighborhood. Additionally, the graphical pattern of hourly foot traffic represents the predominant land use of the district. Three peaks of foot traffic indicate flooding office 
workers during morning and evening rush hour as well as lunchtime. Whereas, a dull plateau of foot traffic from morning to afternoon is observed in residential neighborhoods.

Pedestrian behavior is highly dependent on thermal comfort. We observed pedestrians' behavior from paired sidewalks. From May to June, when the average air temperature exceeds $25^{\circ} \mathrm{C}$, we observed that people tend to jump the street to move from one side of the street to the other, seeking shade from the scorching sun, at solar radiation greater than $1248 \mathrm{Wh} / \mathrm{m}^{2}$. Data collected from the new automatic monitoring method of pedestrians can enable urban designers and transportation planners to analyze the physical setting of the pedestrian thoroughfare and how people react to the setting. That is, the new monitoring method can help in planning for streets and neighborhoods to promote walking; in turn, we can encourage cities to be less dependent on the automobile and to be more sustainable.

There are limitations on exploring walking behavior using automated pedestrian monitoring, such as the physical characteristics of sidewalks, including microclimate, design, and other factors that need to be considered to relate walking behavior to environmental characteristics and to predict pedestrian behavior. As a next step, we will recreate the microclimates of sidewalks using computer simulation to explore the thermal comfort threshold in detail.

Funding: This research was partly funded by University of Ulsan. (grant number: 2020-0641).

Acknowledgments: The authors express gratitude to Martin Lagache and Jon Lee from Placemeter Inc., for introducing data processing mechanisms and providing data.

Conflicts of Interest: The author declare no conflict of interest.

\section{References}

1. Appleyard, D. Livable Streets; University of California Press: Berkeley, CA, USA, 1980.

2. Lawrence, F.; Engelke, P. The Built Environment and Human Activity Patterns: Exploring the Impacts of Urban Form on Public Health. J. Plan. Lit. 2001, 16, 202-218.

3. Lee, C.; Moudon, A.V. Physical activity and environment research in the health field: Implications for urban and transportation planning practice and research. J. Plan. Lit. 2004, 19, 147-181. [CrossRef]

4. De Montigny, L.; Ling, R.; Zacharias, J. The Effects of Weather on Walking Rates in Nine Cities. Environ. Behav. 2012, 44, 821-840. [CrossRef]

5. Gehl, J. Life Between Buildings; Van Nostrand Reinhold: New York, NY, USA, 1987.

6. Hoogendoorn, S.P.; Daamen, W. Pedestrian behavior at bottlenecks. Transp. Sci. 2005, 39, 147-159. [CrossRef]

7. Rasouli, A.; Kotseruba, I.; Tsotsos, J.K. Understanding pedestrian behavior in complex traffic scenes. IEEE Trans. Intell. Veh. 2017, 3, 61-70. [CrossRef]

8. Chen, Z.; Ngai, D.C.; Yung, N.H.C. Pedestrian behavior prediction based on motion patterns for vehicle-to-pedestrian collision avoidance. In Proceedings of the 2008 11th International IEEE Conference on Intelligent Transportation Systems, Beijing, China, 12-15 October 2008; pp. 316-321.

9. Basch, C.H.; Ethan, D.; Zybert, P.; Basch, C.E. Pedestrian behavior at five dangerous and busy Manhattan intersections. J. Community Health 2015, 40, 789-792. [CrossRef] [PubMed]

10. Nikolopoulou, M.; Baker, N.; Steemers, K. Thermal Comfort in Outdoor Urban Spaces: The Human Parameter. Sol. Energy 2001, 70, 227-235. [CrossRef]

11. Hashimoto, Y.; Gu, Y.; Hsu, L.T.; Iryo-Asano, M.; Kamijo, S. A probabilistic model of pedestrian crossing behavior at signalized intersections for connected vehicles. Transp. Res. Part C Emerg. Technol. 2016, 71 , 164-181. [CrossRef]

12. Hoogendoorn, S.P.; Bovy, P.H. Pedestrian route-choice and activity scheduling theory and models. Transp. Res. Part B Methodol. 2004, 38, 169-190. [CrossRef]

13. Lin, T.P. Thermal Perception, Adaptation, and Attendance in a Public Square in Hot and Humid Regions. Build. Environ. 2009, 44, 2017-2026. [CrossRef]

14. Zacharias, J. Microclimate and Downtown Open Space Activity. Environ. Behav. 2001, 33, 296-315. [CrossRef]

15. Fukuyo, K. Application of computational fluid dynamics and pedestrian-behavior simulations to the design of task-ambient air-conditioning systems of a subway station. Energy 2006, 31, 706-718. [CrossRef]

16. Whyte, W. The Social Life of Small Urban Spaces; Project for Public Spaces: New York, NY, USA, 1980. 
17. Ikeda, T.; Chigodo, Y.; Rea, D.; Zanlungo, F.; Shiomi, M.; Kanda, T. Modeling and prediction of pedestrian behavior based on the sub-goal concept. Robotics 2013, 10, 137-144.

18. Camillen, F.; Caprì, S.; Garofalo, C.; Ignaccolo, M.; Inturri, G.; Pluchino, A.; Rapisarda, A.; Tudisco, S. Multi agent simulation of pedestrian behavior in closed spatial environments. In Proceedings of the 2009 IEEE Toronto International Conference Science and Technology for Humanity (TIC-STH), Toronto, ON, Canada, 26-27 September 2009; pp. 375-380.

19. Yi, S.; Li, H.; Wang, X. Pedestrian behavior understanding and prediction with deep neural networks. In European Conference on Computer Vision; Springer: Cham, Switzerland, 2016; pp. 263-279.

20. Chatzidimitriou, A.; Yannas, S. Microclimate development in open urban spaces: The influence of form and materials. Energy Build. 2015, 108, 156-174. [CrossRef]

21. Levinson, H.S.; Wynn, F.H. Effects of density on urban transportation requirements. Highw. Res. Rec. 1963, 2 , 38-64.

22. Cervero, R.; Kockelman, K. Travel demand and the 3Ds: Density, diversity, and design. Transp. Res. Part D Transp. Environ. 1997, 2, 199-219. [CrossRef]

23. Handy, S. Regional Versus Local Accessibility: Implications for Nonwork Travel. Transp. Res. Rec. 1993, 1400, 58-66.

24. Cervero, R.; Radisch, C. Travel Choices in Pedestrian Versus Automobile Oriented Neighborhoods; UC Berkeley, University of California Transportation Center: Berkeley, CA, USA, 1995; Available online: https: //escholarship.org/uc/item/7cn9m1qz (accessed on 22 September 2020).

25. Rioux, L.; Werner, C.M.; Mokounkolo, R.; Brown, B.B. Walking in two French neighborhoods: A study of how park numbers and locations relate to everyday walking. J. Environ. Psychol. 2016, 48, 169-184. [CrossRef]

26. Lee, C.; Moudon, A. Correlates of walking for transportation or recreation purposes. J. Phys. Act. Health 2006, 3, S77-S98. [CrossRef]

27. Ewing, R.; Cervero, R. Travel and the built environment: A meta-analysis. J. Am. Plan. Assoc. 2010, 76, 265-294. [CrossRef]

28. Ewing, R.; Greenwald, M.; Zhang, M.; Walters, J.; Feldman, M.; Cervero, R.; Kassa, S.; Thomas, J. Traffic generated by mixed-use developments-six-region study using consistent built environmental measures. J. Urban Plan. Dev. 2011, 137, 248-261. [CrossRef]

29. Robin, T.; Antonini, G.; Bierlaire, M.; Cruz, J. Specification, estimation and validation of a pedestrian walking behavior model. Transp. Res. Part B Methodol. 2009, 43, 36-56. [CrossRef]

30. Li, S. User's Behavior of Small Urban Spaces in Winter and Marginal Seasons. Archit. Behav. 1994, 10, 95-109.

31. Wu, H.; Kriksic, F. Designing for pedestrian comfort in response to local climate. J. Wind Eng. Ind. Aerodyn. 2012, 104, 397-407. [CrossRef]

32. Zacharias, J.; Bernhardt, T.; De Montigny, L. Computer-simulated pedestrian behavior in shopping environment. J. Urban Plan. Dev. 2005, 131, 195-200. [CrossRef]

33. Dustin, D.; Aldstadt, J.; Whalen, J.; Melly, S.; Gortmaker, S. Validation of Walk Score ${ }^{\circledR}$ for Estimating Neighborhood Walkability: An Analysis of Four US Metropolitan Areas. Int. J. Respir. Public Health 2011, 8, 4160-4179.

34. McFarland, M. Placemeter offers a fast, easy look at pedestrian traffic. The Washington Post. 29 June 2015. Available online: https://www.pressreader.com/usa/the-washington-post/20150629/281831462386141 (accessed on 3 August 2015).

35. Aultman-Hall, L.; Lane, D.; Lambert, R. Assessing Impact of Weather and Season on Pedestrian Traffic Volumes. Transp. Res. Rec. 2009, 2140, 35-43. [CrossRef]

36. Culjat, B.; Erskine, R. Climate-Responsive Social Space: A Scandinavian Perspective. In Cities Designed for Winter; Building Book Ltd.: Helsinki, Finland, 1988.

37. Santamouris, M.; Papanikolaou, N.; Livada, I.; Koronakis, I.; Georgakis, C.; Argiriou, A.; Assimakopoulos, D.N. On the Impact of Urban Climate on the Energy Consumption of Buildings. Urban Environ. 2001, 70, $201-216$. [CrossRef]

38. Arens, E.; Bosselmann, P. Wind, sun and temperature-Predicting the thermal comfort of people in outdoor spaces. Build. Environ. 1989, 24, 315-320. [CrossRef]

39. Givoni, J.; Noguchi, M.; Saaroni, H.; Pochter, O.; Yaacov, Y.; Feller, N. Outdoor Thermal Comfort Research Issues. Energy Build. 2003, 35, 77-86. [CrossRef] 
40. Stathopoulos, T.; Wu, H.; Zacharias, J. Outdoor Human Comfort in an Urban Climate. Build. Environ. 2004, 39, 297-305. [CrossRef]

41. Dimoudi, A.; Nikolopoulou, M. Vegetation in the Urban Environment: Microclimatic Analysis and Benefits. Spec. Issue Urban Res. 2003, 35, 69-76. [CrossRef]

42. Newman, P.G.; Kenworthy, J.R. Cities and Automobile Dependence: An International Sourcebook; Avebury Technical: Brookfield, VT, USA, 1991.

43. Rust, E. Should we be concerned about Placedmeter-an app which monitors street views from apartment window? The Guardian. 2014. Available online: https://www.theguardian.com/cities/2014/oct/27/-spplacemeter-app-street-view-window-new-york-smartphone (accessed on 22 September 2020).

44. Nikolopoulou, M. Thermal Comfort and Psychological Adaptation as a Guide for Designing Urban Spaces. Energy Build. 2003, 35, 95-101. [CrossRef]

45. Bosselmann, P.; Dake, K.; Kraus, M. Sun, Wind, and Comfort: A Field Study of Thermal Comfort in San Francisco; Work. Paper; Center for Environmental Design Research, University of California, Berkeley: Berkeley, CA, USA, 1988; Volume 627.

46. City and County of San Francisco. Downtown: An Area Plan of the Master Plan of the City and County of San Francisco; City of San Francisco: San Francisco, CA, USA, 1985.

47. Adler, M. New Yorkers Protest Long Shadows Cast By New Skyscrapers. NPR Press, 23 April 2014. Available online: https://www.npr.org/2014/04/23/305643904/nyc-s-tall-skyscrapers-cast-super-shadows-on-centralpark (accessed on 22 September 2020).

48. Bernstein, F.A. Supersizing Manhattan: New Yorkers rage against the dying of the light. The Guardian. 2015. Available online: https:/www.theguardian.com/cities/2015/jan/16/supersizing-manhattan-new-yorkers-rageagainst-the-dying-of-the-light (accessed on 22 September 2020).

49. Placemeter Website. Available online: https://www.placemeter.com/ (accessed on 30 August 2015).

50. Wundermap Website. Available online: http://www.wunderground.com/wundermap/ (accessed on 30 August 2015).

51. NOAA. Station Data Inventory, Access \& History. Available online: https://www.ncdc.noaa.gov/data-access/ land-based-station-data/station-metadata (accessed on 27 August 2020).

52. Handy, S. Methodologies for exploring the link between urban form and travel behavior. Transp. Res. Part D Transp. Environ. 1996, 1, 151-165. [CrossRef]

53. Eliasson, I.; Knez, I.; Westerberg, U.; Thorsson, S.; Lindberg, F. Climate and Behavior in a Nordic City. Landsc. Urban Plan. 2007, 82, 72-84. [CrossRef]

54. New York City, 2015 Street Tree Census. Available online: https://data.cityofnewyork.us/Environment/2015Street-Tree-Census-Tree-Data/pi5s-9p35 (accessed on 22 September 2020). 